\title{
DETERMINATION OF THE KINETICS OF CURING AND THE HEAT CAPACITY OF AN EPOXY RESIN BY DIFFERENTIAL SCANNING CALORIMETRY
}

\section{J. A. Basford}

\section{OAK RIDGE Y-12 PLANT} OAK RIDGE. TENNESSEE

\section{CARBIDE}

prepared for the U.S. ENERGY RESEARCH AND DEVELOPMENT ADMINISTRATION under U.S. GOVERNMENT Contract W-7405 eng 26 


\section{DISCLAIMER}

This report was prepared as an account of work sponsored by an agency of the United States Government. Neither the United States Government nor any agency Thereof, nor any of their employees, makes any warranty, express or implied, or assumes any legal liability or responsibility for the accuracy, completeness, or usefulness of any information, apparatus, product, or process disclosed, or represents that its use would not infringe privately owned rights. Reference herein to any specific commercial product, process, or service by trade name, trademark, manufacturer, or otherwise does not necessarily constitute or imply its endorsement, recommendation, or favoring by the United States Government or any agency thereof. The views and opinions of authors expressed herein do not necessarily state or reflect those of the United States Government or any agency thereof. 


\section{DISCLAIMER}

Portions of this document may be illegible in electronic image products. Images are produced from the best available original document. 
Reference to a company or product name does not imply approval or recommendation of the product by Union Carbide Corporation or the U.S. Energy Research and Development Administration to the exclusion of others that may meet specifications.

Printed in the United States of America. Available from National Technical Information Service

U.S. Department of Commerce

5285 Port Royal Road, Springfield, Virginia 22161

Price: Printed Copy $\$ 4.00$; Microfiche $\$ 2.25$

This report was prepared as an account of work sponsored by the United States Government. Neither the United States nor the Energy Research and Development Administration/United States Nuclear Regulatory Commission, nor any of their employees, nor any of their contractors, subcontractors, or their employees, makes any warranty, express or implied, or assumes any legal liability or responsibility for the accuracy, completeness or usefulness of any information, apparatus, product or process disclosed, or represents that its use would not infringe privately owned rights. 


\title{
DETERMINATION OF THE KINETICS OF CURING AND THE HEAT CAPACITY OF AN EPOXY RESIN BY DIFFERENTIAL SCANNING CALORIMETRY
}

\author{
J. A. Basford
}

Laboratory Development Department Y-12 Development Division

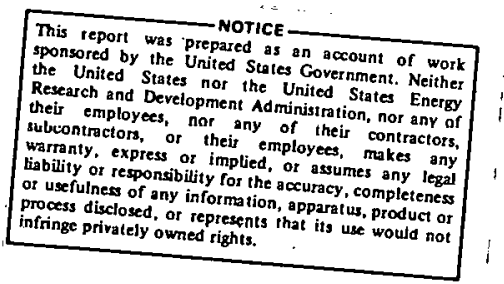

Oak Ridge Y.12 Plant

P. O. Box Y, Oak Ridge, Tennessee 37830

Prepared for the US Energy Research and Development Administration Under US Government Contract W-7405-eng-26

OT $N-7405-E X G-26$ 


\section{ABSTRACT}

Two techniques were developed for determining the kinetic parameters of chemical reactions from differential scanning calorimeter data. In one technique, variation with time of the heat gain or loss as reactions proceed can be used to determine the order, rate constant, activation energy, and heat of reaction. In the second technique, variation with time of the glass transition temperature of certain materials can be used to determine the order, rate constant, and activation energy. An application has been made to the curing of an epoxy resin. 


\section{CONTENTS}

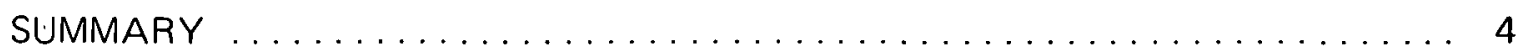



KINETICS OF CURING AND HEAT CAPACITY OF AN EPOXY RESIN $\ldots \ldots \ldots 6$

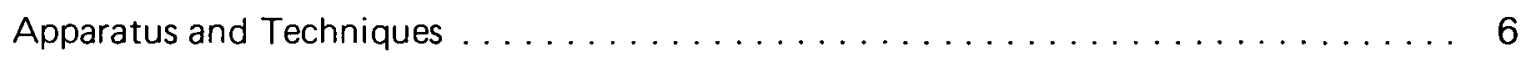

Results and Discussion .............................. 6

Determination of Kinetic Parameters by Heat Evolution Methods . . . . . . . 6

Determination of Kinetic Parameters by the Glass-Transition-

Temperature Method ...................... 9

Comparison of the Two Methods . . . . . . . . . . . . . . . . . . 11

Application of the Kinetic Parameters to the Heat-Treatment Cycles . . . . . . . 12

Effects of Changes in Stoichiometry and Inert Diluents . . . . . . . . . . . 15

REFERENCES ........................... 18

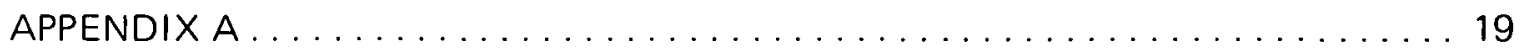

Derivation of Equations for Determining Kinetic Parameters from Isothermal

Differential Scanning Calorimetry Data. . . . . . . . . . . . . . . . 19

First-Order Reactions . . . . . . . . . . . . . . . . . . . . . . . 19

Second-Order Reactions . . . . . . . . . . . . . . . . . . . . . 20

Third-Order Reactions ............................. 21

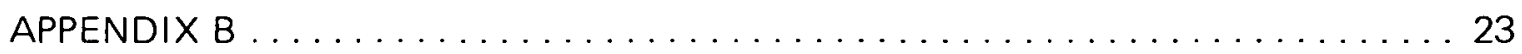

Derivation of Equations for Determining Kinetic Parameters from

Glass-Transition-Temperature Data .............. 23



Use of Kinetic Parameters in Determınıng Extent of Cure $\ldots \ldots \ldots \ldots \ldots \ldots \ldots$ 


\section{SUMMARY}

Differential scanning calorimeters (DSC) measure the rate at which energy must be applied to a sample or to a reference holder to maintain them at the same temperature. Two techniques were developed for obtaining kinetic data using a DSC.

If, at a given temperature, a sample is undergoing a reaction involving an energy change, the output of the DSC is proportional to the rate of heat flow due to that reaction. Equations were derived in which the variation with time of the DSC output could be used to determine reaction orders, enthalpy, rates, and activation energies. The exothermic curing of a B-staged epoxy resin (ERL-2258/ZZL-0820) was studied as an example and was found to follow second-order kinetics with a rate constant of:

$$
k_{2}=959 \mathrm{e}^{-7448 / \mathrm{T}} \mathrm{g} \mathrm{cal}^{-1} \mathrm{sec}^{-1} \text {. }
$$

For amorphous materials, a change in heat capacity occurs as they go from a glassy to a liquid state at the glass transition temperature $(T \mathrm{~g})$. The $\mathrm{T}_{\mathrm{g}}$ of some materials varies in a regular manner with the extent of polymerization. Equations were derived that relate this variation of $\mathrm{Tg}$ with the kinetic parameters. Curing of the B-staged epoxy resin was studied by determining the $\mathrm{Tg}$ from DSC heat-capacity curves for samples heat treated for various times and temperatures. The results were found to correlate well with those obtained using the first technique.

The extent of cure was calculated using kinetic data for a typical slow curing cycle. The extent of cure calculated from the $T_{g}$ measured for a sample heat treated over that cycle corresponded closely with that calculated from kinetic data. 


\section{INTRODUCTION}

This study was undertaken at the Oak Ridge $Y-12$ Plant(a) to develop techniques which could be used to determine the kinetic parameters of chemical reactions using a DSC.

Exothermic and endothermic reactions involve heat transfers at rates which decrease with time in the same proportion that the concentrations of the reacting species decrease. The DSC, with its fast response and high sensitivity, is well suited to making kinetic studies of such reactions. Previous workers (1) have reported techniques for determining kinetic parameters from data obtained under nonisothermal conditions. Interpretation of the results is not straightforward(2) and becomes virtually impossible when simultaneous reactions with different activation energies occur. Rogers (3) found that plots of $\log h$ vs $t$ gave straight lines for first-order, isothermal reactions, where $h$ is the DSC output and $t$ is time. Gray (4) determined the fraction of heat evolved at $t$ by planimeter measurements and equated it with the fraction of cure of an epoxy resin. Comparison was then made with the $\mathrm{Tg}$. In this work, equations were derived which relate $h$, taken under isothermal conditions, with the kinetic parameters. They were applied in the determination of rate, order, activation energy, and heat of the curing reaction of an epoxy resin.

For many polymers, $\mathrm{Tg}$ varies in a regular manner with molecular weight. (5) Equations were derived which relate $\mathrm{Tg}$ changes with the kinetic parameters and were used to determine the rate, order, and activation energy of the curing of an epoxy resin.

The utility of the data reported herein is that they may be used to calculate rather than measure the degree of cure obtained from a variety of proposed heat-treatment cycles. An example of such a curing cycle is given in which the calculated degree of cure was found to correspond closely with the measured degree.

Effects of changes of stoichiometry and addition of inert diluents upon the determination of the kinetic parameters were also studied.

(a) Operated by the Union Carbide Corporation's Nuclear. Division for the US Energy Research and Development Administration. 


\section{KINETICS OF CURING AND HEAT CAPACITY OF AN EPOXY RESIN}

\section{APPARATUS AND TECHNIQUES}

Thermal measurements and heat treatments were performed on a Perkin-Elmer Model DSC-2 differential scanning calorimeter (DSC). This instrument contains a matched pair of 9-mm-diameter sample holders with integral heating elements and platinum resistance thermometers. Heating-element power is derived alternately at $85 \mathrm{~Hz}$ from two sources. The average temperature of the two holders is controlled by a feedback loop and a digital temperature programmer controlling one power supply. The temperature difference between the holders is nulled by the application of power from the second supply and feedback loop to the holder at the lower temperature. The power from this second source, which is the time derivative of the transition or reaction energy or of the heat capacity of the sample, is recorded as a function of time or temperature. Samples of 0.1 to $200 \mathrm{mg}$ can be studied over the range trom 100 to $1000 \mathrm{~K}$ at heatıng or coolıng rates trom $\dot{U}$ to $320 \mathrm{~K} \mathrm{~min}^{-1}$ and at sensitivities down to $0.01 \mathrm{mcal} \mathrm{sec}^{-1}$. Instrument response is faster, the sample size smaller, and the output more physically meaningful than with conventional differential thermal analysis instruments.

In this work, sample sizes ranged from 4 to $20 \mathrm{mg}$. Glass transition temperatures $\left(\mathrm{Tg}_{\mathrm{g}}\right)$ were determined at heating rates of $5 \mathrm{deg}^{\mathrm{min}}-1$ and were defined as the temperature at which one half the change in heat capacity (difference between the glass and liquid states) had occurred. The heat of fusion of indium(6) at $429.8 \mathrm{~K}$ and the heat capacity of aluminum oxide (7) were used as calibrating standards for the determination of the reaction and transition energies and of the heat capacity of the resin.

The epoxy resin used in this study was a 31:9 mixture. of ERL-2258/ZZL-0820.(b) ERL-2258 consists of $50 \%$ diglycidyl ether of bisphenol-A (DGEBA) and $50 \%$ bis(2,3-epoxycyclopentyl) ether. ZZL-0820 consists of $53 \%$ m-phenylenediamine, $34 \%$ p.p'-methylenedianiline and $13 \%$ DGEBA. The mixture was heat treated at $358 \mathrm{~K}$ for two hours to effect a partial cure, or B-stage.

\section{RESULTS AND DISCUSSION}

Three kinds of data were obtained from the DSC thermograms: (1) rates of heat evolution from the curing reaction of the resin, (2) relative and absolute heal capacities, and (3) transition energies. Rates, the order, and the activation energy of the curing reaction were calculated from the rates of heat evolution at different temperatures. Glass transition temperatures were obtained from the relative heat capacities.

\section{Determination of Kinetic Parameters by Heat-Evolution Methods}

Samples were heated to 423 or $473 \mathrm{~K}$ at $320 \mathrm{deg} \mathrm{min}^{-1}$, and the rate that heat evolved per gram, h, from the isothermal exothermic curing reaction was plotted as a function of time.

(b) A product of the Union Carbide Corporation 


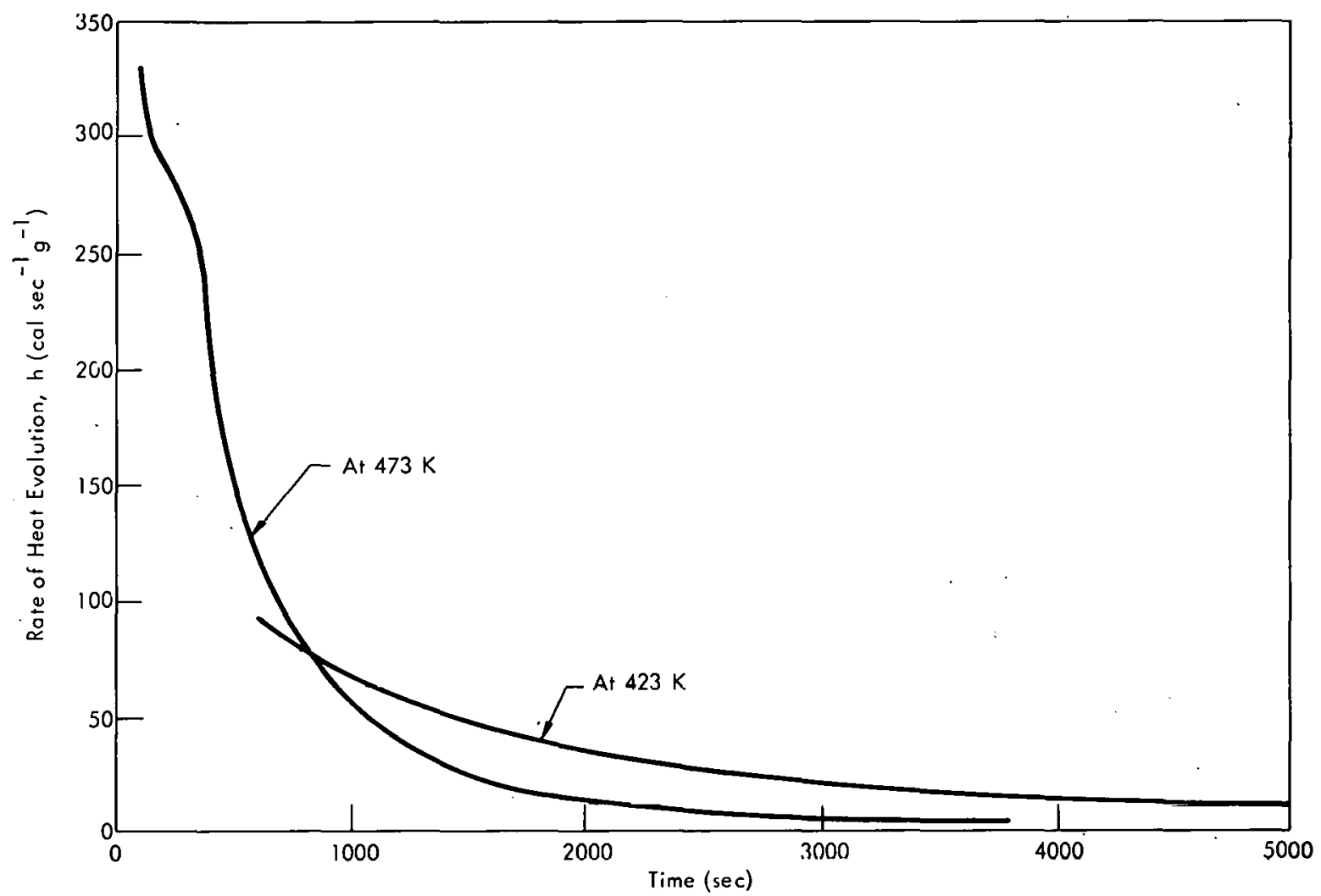

Figure 1. RATE OF HEAT EVOLUTION AT TWO TEMPERATURES FOR CURING AN EPOXY RESIN. IThe Initial Irregularity in the Curve of the $473 \mathrm{~K}$ Run is Due to Slight Temperature Changes in the Heat Sink)

Figure 1 is a graph of the typical data obtained. During the initial 400 seconds of the $473 \mathrm{~K}$ run, the instrument heat sink was not close enough to thermal equilibrium for accurate data to be taken at the high sensitivities used. At 5000 seconds into the $423 \mathrm{~K}$ run and at 3800 seconds into the $473 \mathrm{~K}$ run, the uncertainty in the rate of heat evolution increased because of very slight instrument drift, and the runs were therefore terminated before completion of cure. The area under each of the two curves should be equal to the heat of the curing reaction, $\Delta \mathrm{H}$. Planimeter determinations of such areas were found to vary greatly, largely because of the inaccurate curve traced at the start of each run.

However, the shape of the major portions of the curves can be analyzed by equations derived in Appendix $A$ for first, second, and third-order kinetics to yield $\Delta H$, the activation energy $E^{\ddagger}$, and the rate constants for the curing reaction, $k_{n}$. For first-order reactions plots of In $h$ vs $t$ give straight lines according to Equation $A-1$; but, with this epoxy resin, such plots gave curved lines, indicating that the curing reaction is not first order. Plots of $h^{-1 / 2}$ vs $t$ give straight lines for second-order reactions according to Equation A-7. As noted in Figure 2 , these data lie on straight lines, demonstrating that second-order kinetics are followed. The slight curvature after 3500 seconds for the $423 \mathrm{~K}$ heat treatment is due to a very slight instrument drift. These points were not used in calculations of slope and intercept. The points taken before 400 seconds were likewise not used because thermal equilibrium of the heat sink. with the sample holders had not yet occurred. 


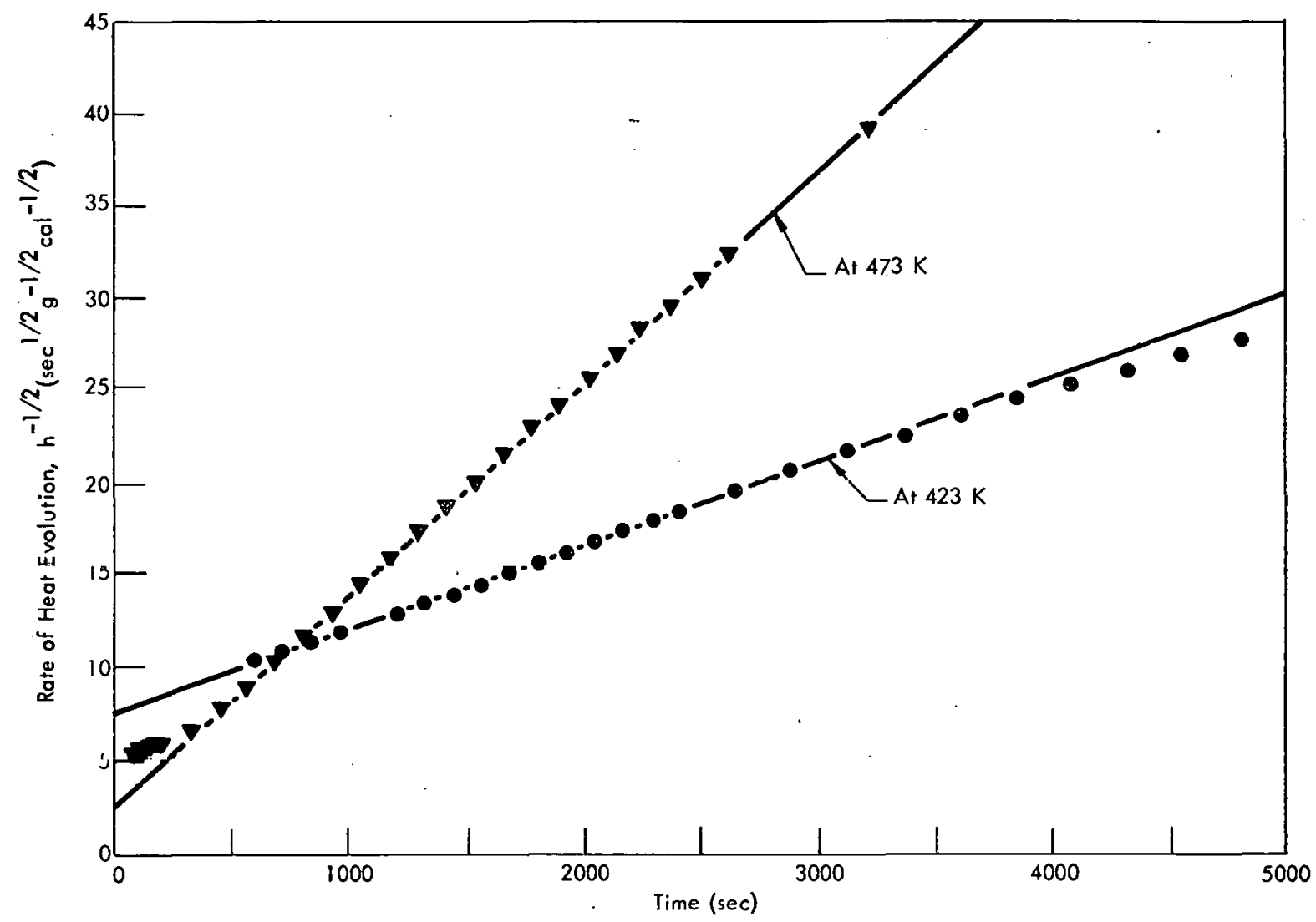

Figure 2. SECOND-ORDER KINETIC PLOT OF T̈HE RATE-OF-HEAT-EVOLUTION DATA AT TWO TEMPERATURES OF HEAT TREATMENT. (Data Taken at Less Than 500 Seconds and More Than 4000 Seconds were not Used in Computing the Least-Squares Lines)

The second-order reaction constant, $k_{2}$, was computed from the squares of the slopes of the lines in Figure 2 and was found to have values of $2.07 \times 10^{-5}$ and $1.34 \times 10^{-4} \mathrm{~g} \mathrm{cal}^{-1} \mathrm{sec}^{-1}$ at 423 and $473 \mathrm{~K}$, respectively. The activation energy is thus $14.8 \mathrm{kcal} \mathrm{mol}^{-1}$, and the second-order rate constant at temperature $T$ is given by:

$$
k_{2}=959 \mathrm{e}^{-7448 / \mathrm{T}} \mathrm{g} \mathrm{cal}^{-1} \mathrm{sec}^{-1} \text {. }
$$

The reaction half times were computed from the ratio of the intercept to the slope and were 1664 and 202.4 seconds at 423 and $473 \mathrm{~K}$, respectively. The initial rate of heat evolution is the reciprocal of the square of the intercept and is $1.742 \times 10^{-2} \mathrm{cal} \mathrm{g}^{-1} \mathrm{sec}^{-1}$ at $423 \mathrm{~K}$ and $1.821 \times 10^{-1} \mathrm{cal} \mathrm{g}^{-1} \mathrm{sec}^{-1}$ at $473 \mathrm{~K}$. The area under the curve of Figure 1 is $\Delta \mathrm{H}$, which is the reciprocal of the product of the slope and intercept of the lines in Figure 2, and was computed to be $29.0 \mathrm{cal} \mathrm{g}^{-1}$. Planimeter measurement of that area gave $21.3 \mathrm{cal} \mathrm{g}^{-1}$, but the kinetic-data computation is more reliable because of the uncertainties in $h$ during the inilial part of the runs.

Using the method of Uricheck, (1) attempts were made to obtain kinetic parameters by measuring the areas between the initial and fully cured heat-capacity curves obtained by scanning at $1.25 \mathrm{deg} \mathrm{min}-1$ over the range from 323 to $523 \mathrm{~K}$. A sensitivity of $0.02 \mathrm{mcal}$ $\mathrm{sec}^{-1}$ for a full-scale recorder deflection was required. The area is approximately the sum of 
the heat of reaction and the product $\Delta C_{p} \Delta T$, where $\Delta C_{p}$ is the difference in heat capacity of the uncured and cured resin and $\Delta T$ is the difference between $T_{g_{\infty}}$ and $T_{g_{0}}$, the final and initial $\mathrm{T}_{\mathrm{g}}$ values. However, as a significant portion of the curing reaction had not taken place during this heat treatment, as the slower scan speeds required to get complete reaction require even greater sensitivity, and as higher final temperatures could not be used without degrading the resin, this effort to obtain $\Delta \mathrm{H}$ had to be abandoned.

\section{Determination of Kinetic Parameters by the Glass-Transition-Temperature Method}

Amorphous materials exhibit discontinuous changes in their heat capacities and thermal expansions at the temperature at which they change from the glassy to the liquid state. This temperature (actually a temperature range) is called the "glass transition temperature", Tg. here defined as that temperature at which one half the change in heat capacity occurs during a scan of increasing temperature. Because $\mathrm{Tg}$ is slightly dependent on the rate of temperature increase (due to finite thermal conductivity), a slow scan speed of five degrees per minute was used.

The heat capacity of the as-received B-staged resin is shown in Figure 3. Heat capacities of the B-staged resin above $373 \mathrm{~K}$ cannot be directly determined because the heat given off in the curing reaction significantly changes the apparent baseline. Figure 4 shows the heat capacity after a heat treatment of 25 hours at $423 \mathrm{~K}$. During the initial scan of each sample of B-staged resin through the $\mathrm{Tg}$, a large endothermic spike was always found, with an area of $0.838 \mathrm{cal} \mathrm{g}^{-1}$. Subsequent scans were devoid of this feature and exhibited the normal S-shaped curve from which the $\mathrm{T}_{\mathrm{g}}$ could be determined. This phenomenon is probably a result of a bulk stress relaxation of the material or a molecular-level free-volume effect. (8) The endothermic spike was also seen only on the initial scan through the glass transition region of the heat-treated sample in Figure 4 Note that $\mathrm{Tg}$ is greater than the heat-treatment temperature, indicating that the curing reaction continues at temperatures below the $T_{g}$, here accounting for an increase in percent reaction (from 86 to $94 \%$ ), as determined from $\mathrm{Tg}$ and kinetic data. An endothermic spike was also always found whenever the material was held slightly below the $T_{g}$ for a significant period. Its area appeared to increase with time. Kinetic data for the curing reaction below the $\mathrm{Tg}$ could have been determined (vide infra), but were not, due to the lack of time. It is estimated that the redcliur lales are decreased one or two orders of magnitude when the heat-treatment temperature is less than the $\mathrm{Tg}$. The effects of this continuing cure upon other physical properties should be investigated to determine the suitability of use of this material in each potential application, particularly if optimum physical properties are obtained from material cured less than $100 \%$.

The Tgs for many polymers have been shown to be a linear function of the inverse of their molecular weights. (5) Using this assumption, expressions are derived in Appendix B relating

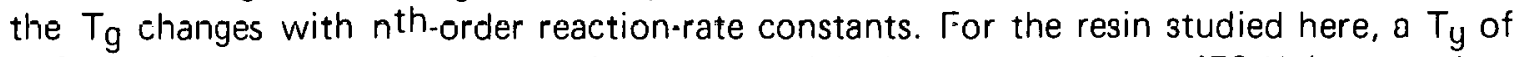
$473 \mathrm{~K}$ was the highest obtained after an overnight heat treatment at $473 \mathrm{~K}$ (greater than $98 \%$ cured) and was thus used as $\mathrm{Tg}_{g_{\infty}}$. Use of higher heat-treatment temperatures for long time periods showed that $\mathrm{Tg}$ went through a maximum at about $473 \mathrm{~K}$, indicating that degradation was occurring. Figure 5 is a first-order plot of the data listed in Table 1 which was obtained by finding the $\mathrm{T}_{\mathrm{g}}$ of samples heat treated at 373,423 , or $473 \mathrm{~K}$ for various times. The high curvature of the lines demonstrates that the curing reaction is not first 




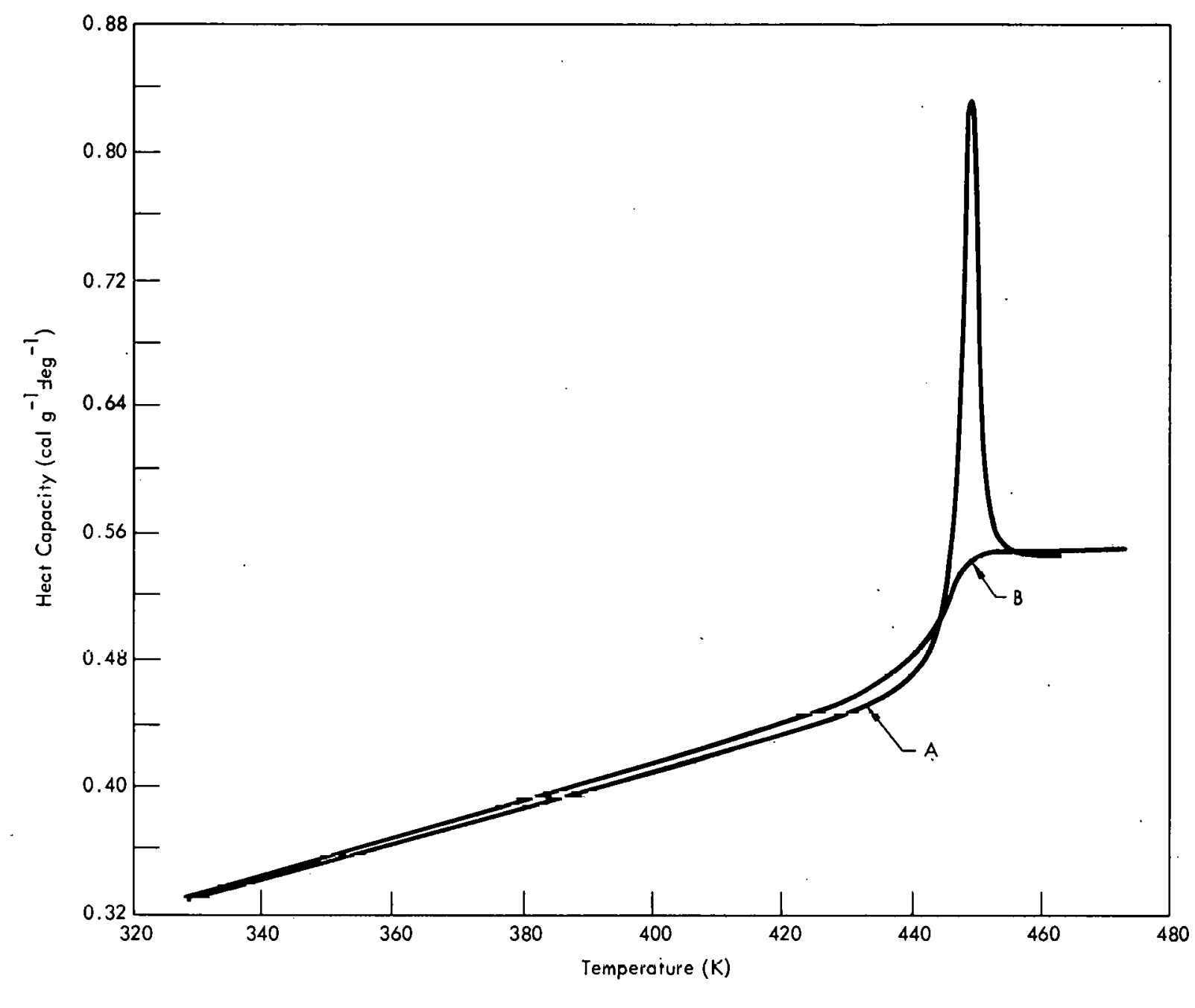

Figure 4. HEAT CAPACITY OF A HEAT.TREATED SAMPLE. (Line A was Obtained ffter r 25.Hour Heat Treatment at

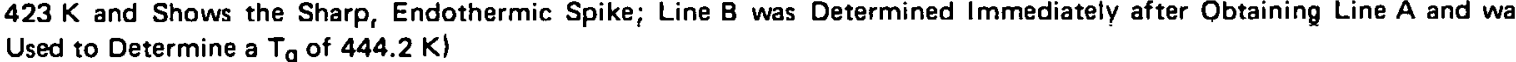

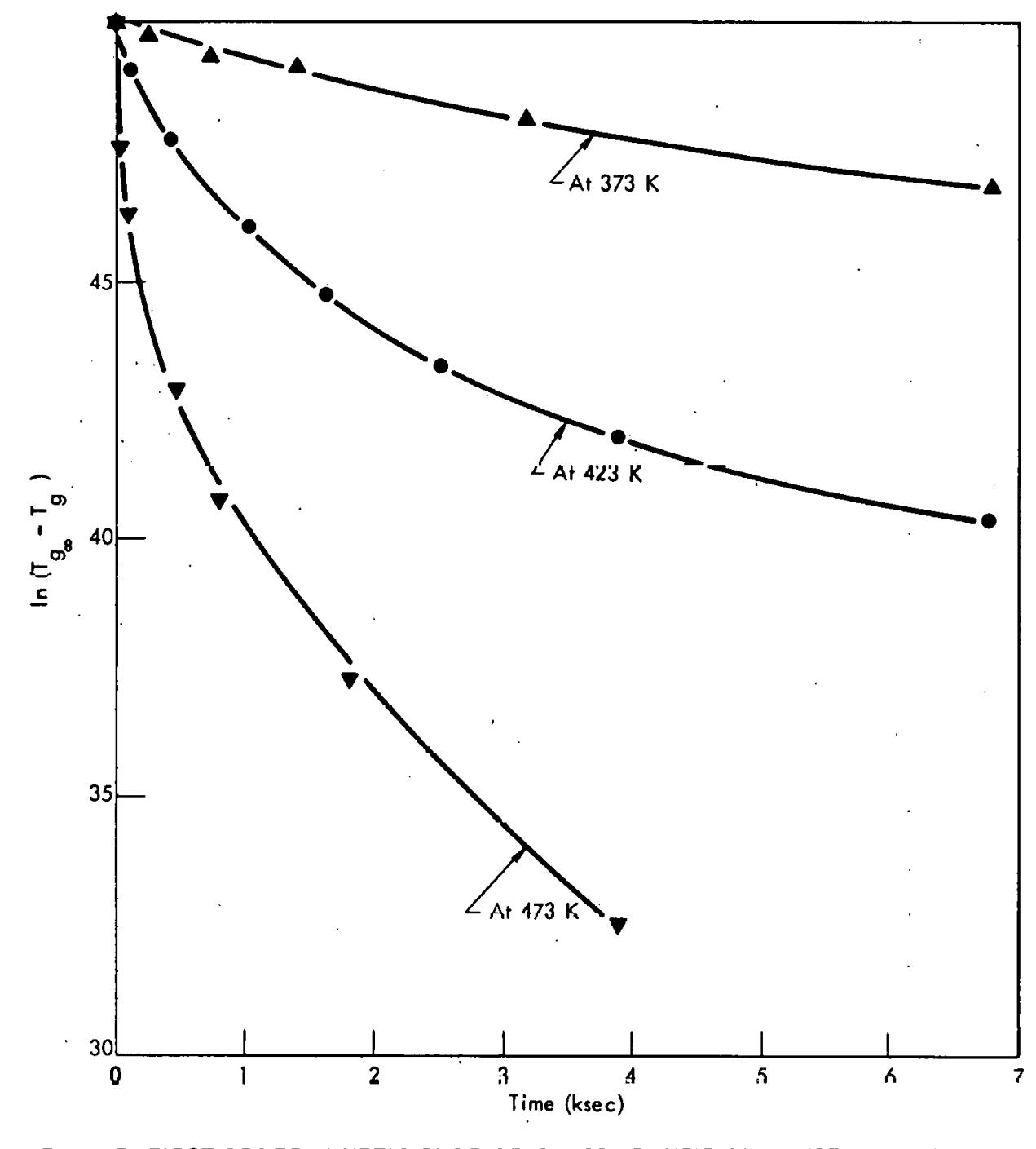

Figure 5. FIRST-ORDER KINETIC PLOT OF GLASS.TRANSITION.TEMPERATURE DATA. (The' High Curvature of the Lines at Each Temperature Demonstrates that First-Order Kinetics are
not Followed During the Curing of this Epoxy Resin) Figure 3. HEAT CAPACITY OF THE B.STAGED EPOXY RESIN. (The Upper Curve was Obtained
from the Initial Heating at 1.25 deg min ${ }^{-1}$ of the Material through the $T_{9}$ Region; the Lower Curve
was Ototained from the Second Heating) 
order. Figure 6 is a second-order plot of the data. Here, the curvatures are small, indicating second-order kinetics are followed and are due to the uncertainties in the final $\mathrm{T}_{\mathrm{g}_{\infty}}$. The slopes are equal to $\mathrm{k} 2 \mathrm{~d} / \mathrm{m}$, where $k_{2}$ is the second-order rate constant, $d$ is the density, and $m$ is the slope of the $T_{g}$ vs $M^{-1}$ plot ( $M$, mol wt). An activation energy of $11.9 \mathrm{kcal} / \mathrm{mol}$ was calculated from the slope of the line in Figure 7.

Using Equation A-10 of Appendix A, the reaction half time at $373 \mathrm{~K}$ was calculated to be 17,720 seconds. Equation A-8 was used to calculate from the heat-evolution data the extent of reaction for the samples listed in Table 1. The $\mathrm{Tgs}$ were plotted against these percentages of reaction in Figure 8. No assumptions concerning the relationship of $\mathrm{Tg}$ with molecular weight were used in this figure. The closeness of all but three points to the line is a measure of the quality of the kinetic data. Those three points, marked "a", correspond to samples which were heat treated at times sufficiently long for the $\mathrm{Tg}$ to eventually exceed the heat-treatment temperature as the curing reaction proceeded. The unknown, but greatly decreased, reaction rate resulting from this phase change was not determined in this work due to a lack of time and was thus not used in the extent of the reaction calculations.

\section{Comparison of the Two Methods}

Equation B-3 (Appendix B) was used to calculate the extent of the reaction based on $\mathrm{T}_{\mathrm{g}}$ data. Figure 9 is a plot of the extent of the reaction obtained from heat-evolution data versus that obtained from $\mathrm{T}_{g}$ data. The assumption that $\mathrm{T}_{\mathrm{g}}$ is a linear function of the reciprocal of the molecular weight is not valid for this system over the whole interval of the curing reaction, as the points in Figure 9 do not lie on the line of unit slope. The straight portion of the line from 0 to $80 \%$ reaction indicates that, over this range, $\mathrm{Tg}$ is proportional to $\mathrm{M}^{-1}$. If it is assumed that $\mathrm{Tg}_{\mathrm{g}}$ was measured incorrectly and that a $\mathrm{T}_{g_{\infty}}$ value of $473 \mathrm{~K}$ does not apply to this resin system at less than $80 \%$ cure, new values ( $\mathrm{T}_{\mathrm{g}}^{\prime}$ and $\mathrm{T}_{\mathrm{g}_{\infty}^{\prime}}$ ) can be calculated from:

$$
\begin{aligned}
& T_{g_{0}^{\prime}}=T_{g_{0}}+\frac{y(0)}{100}\left(T_{g_{\infty}}-T_{g_{0}}\right), \text { or } \\
& T_{g_{\infty}^{\prime}}=T_{g_{0}}+\frac{\dot{y}(100)}{100}\left(T_{g_{\infty}}-T_{g_{0}}\right) .
\end{aligned}
$$

where $y(0)$ and $y(100)$ are the end points of the straight line in Figure 9 which were determined by least-squares analysis. Using the computed values of 333.1 and $434.4 \mathrm{~K}$ for 


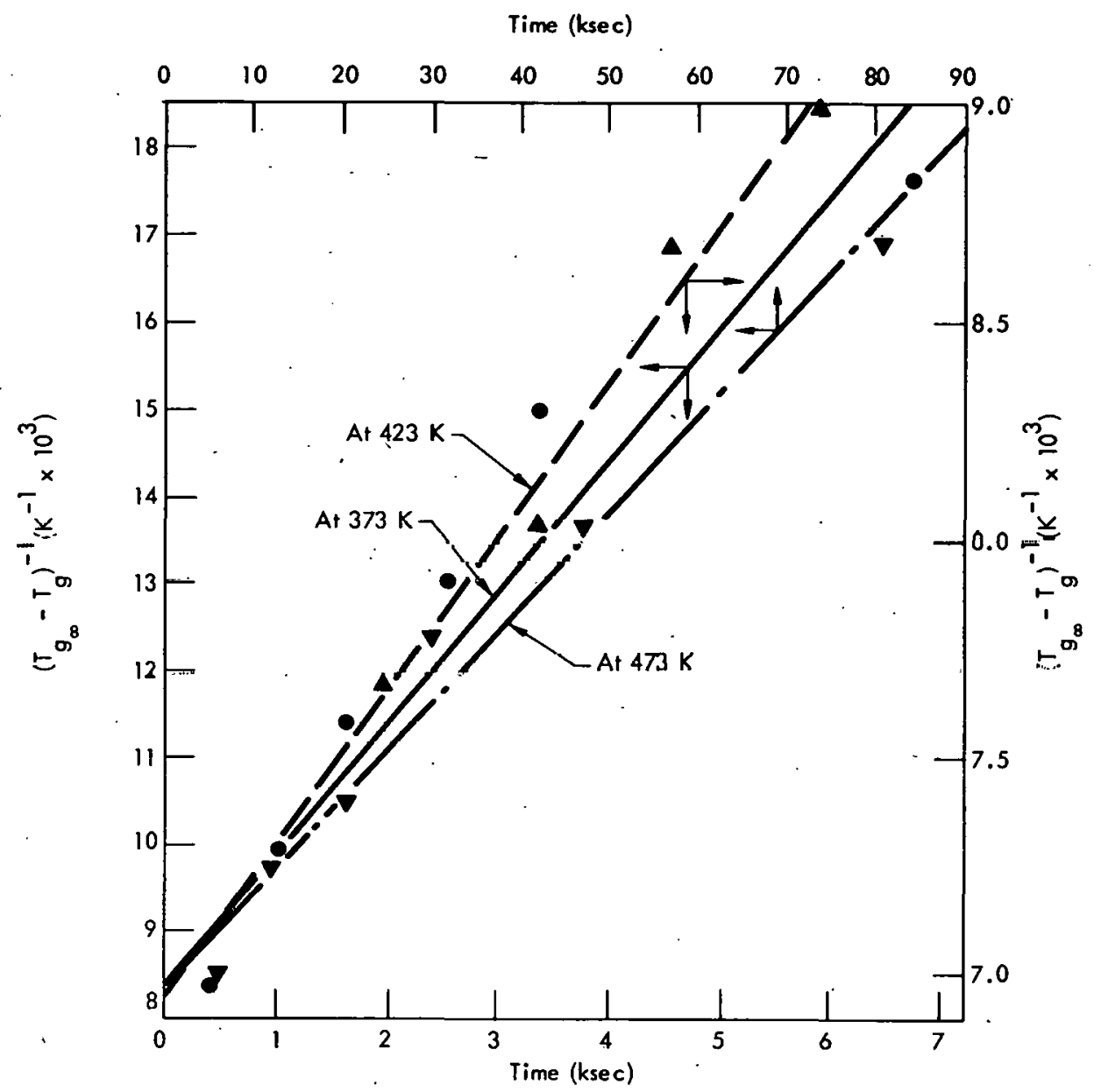

Figure 6. SECOND-ORDER KINETIC PLOT OF GLASS-TRANSITION-TEMPERATURE DATA. (Slopes of the Lines are $\mathrm{k} 2 \mathrm{~d} / \mathrm{m}$; the Slight Curvature of the Lines is Due to an Inaccuracy in the Determination of $T_{g_{\infty}}$ l

$\mathrm{T}_{\mathrm{g}_{\mathrm{o}}^{\prime}}$ and $\mathrm{T}_{\mathrm{g}_{\infty}}^{\prime}$, respectively, the data were replotted in Figure 10 in which the points of less than $80 \%$ reaction now lie on the line of unit slope. Physical interpretation of these data without other data is not possible, but it does suggest that there are some parallel, competing chemical reactions occurring in the last $20 \%$ of the cure which alter the structure of the material. This possibility is not surprising in view of the complex nature of the components of the resin.

Figures 11 and 12 are the same as Figures 6 and 7 except that T $\mathrm{g}_{0}^{\prime}$ and T Tó were used in the calculations. Note that the lines in Figure 11 are straighter than those in Figure 6 . The slope of Figure 12 was used to calculate an activation energy of $14.4 \mathrm{kcal} \mathrm{mol}^{-1}$, in excellent agreement with that calculated from the heat-evolution kinetic data.

\section{Application of the Kinetic Parameters to the Heat-Treatment Cycles}

In Appendix $\mathrm{C}$ an example is given of the use of kinetic data to determine the extent of reaction for a curing heat treatment consisting of a 1.25 deg $\mathrm{min}^{-1}$ increase from 323 to $423 \mathrm{~K}$, a 30 -minute hold at $423 \cdot \mathrm{K}$, and a $1.25 \mathrm{deg} \mathrm{min}^{-1}$ decrease from 423 to $323 \mathrm{~K}$. A 
Simpson's-rule integration of Equation C-2 was performed for the heat treatment of slow heating to $423 \mathrm{~K}$ and holding at $423 \mathrm{~K}$ for 30 minutes. From this integration, the curing reaction was calculated to be $64.0 \% \mathrm{com}$ plete; which, from Figure 8, corresponds to a $\mathrm{T}_{\mathrm{g}}$ of $399 \mathrm{~K}$. From this value it was estimated that the $\mathrm{Tg}_{\mathrm{g}}$ would be about $403 \mathrm{~K}$ after the cooling portion of the heat treatment. A second Simpson's-rule integration was performed using $403 \mathrm{~K}$ as the lower limit on the cooling portion, and this integration resulted in a calculation of $68.5 \%$ completion of cure. The calculations were checked by finding the percent cure from the $\mathrm{Tg}$. During the determination of the $\mathrm{Tg}$ of the sample after the heat-treatment cycle, a large, very sharp, endothermic spike was noted in the $\mathrm{Tg}$ region. A second scan was performed, indicating a $\mathrm{Tg}$ of $407 \mathrm{~K}$, which corresponds to a $73.6 \%$ cure. The agreement between calculations is very good.

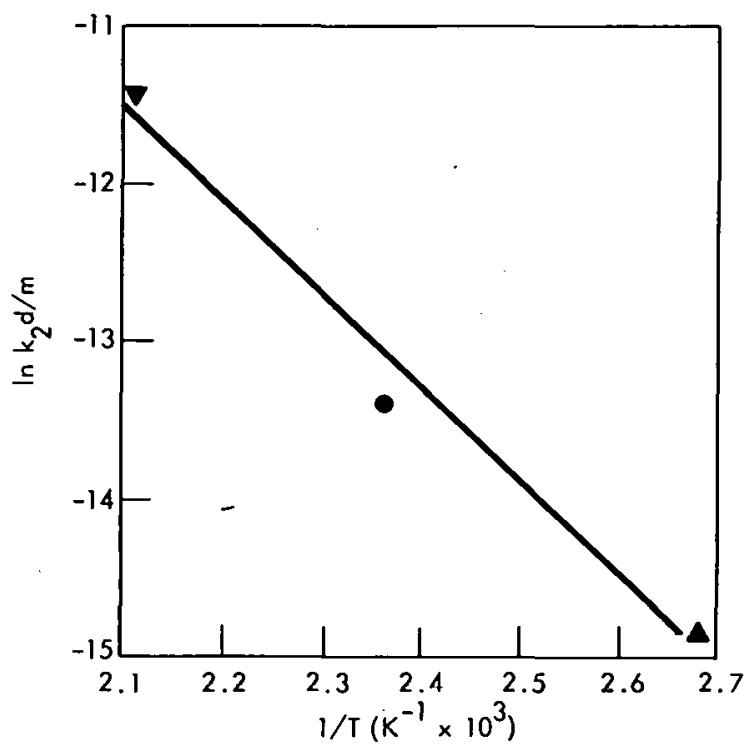

rigure 7. DETERMINATION OF THE ACTIVATION ENERGY FROM GLASS-TRANSITION-TEMPERATURE DATA. (The Activation Energy is the Negative of the Slope Divided by the Gas Constant, R, and is $11.9 \mathrm{kcal}$ $\mathrm{mol}^{-1}$ )



Figure 8. CHANGE IN THE GLASS TRANSITION TEMPERATURE WITH THE DEgREE OF CURE. (The Degree of Cure was Calculated from Heat-Evnlution Kinetic Data and the Time the Samples were Heat Treated at 373, 423, and $473 \mathrm{~K}$; the Points Marked "a" Correspond to Samples whose $T_{g}$ s are Smaller than their Heat-Treatment Temperatures) 


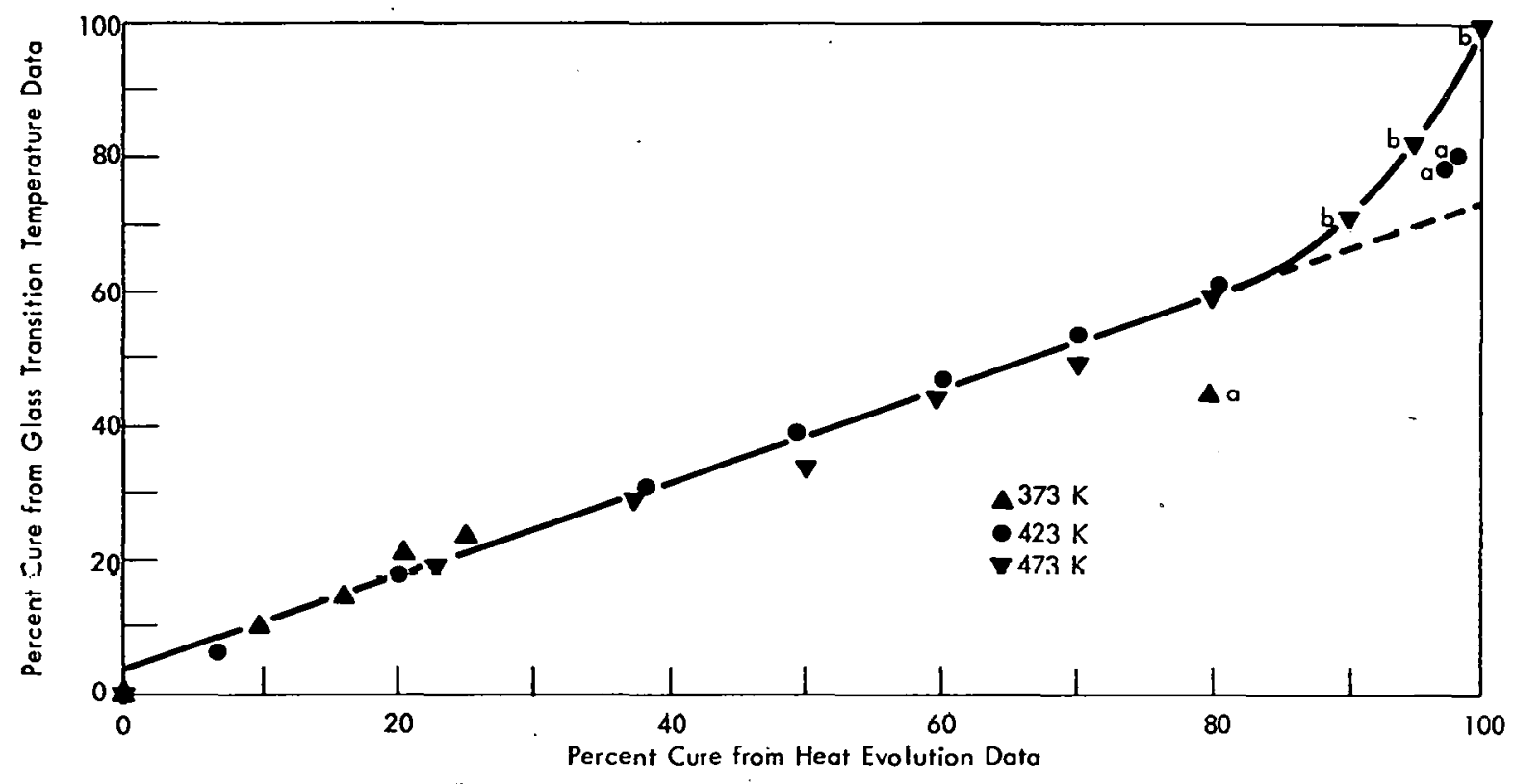

Figure 9. COMPARISON OF HEAT EVOLUTION AND GLASS-TRANSITION-TEMPERATURE KINETIC DATA. (Three Heat-Treatment Temperatures were Used: 373, 423, and $473 \mathrm{~K}$; Points Marked "a" and " $b$ " were not Used in Computing the Least-Squares Straight Line)

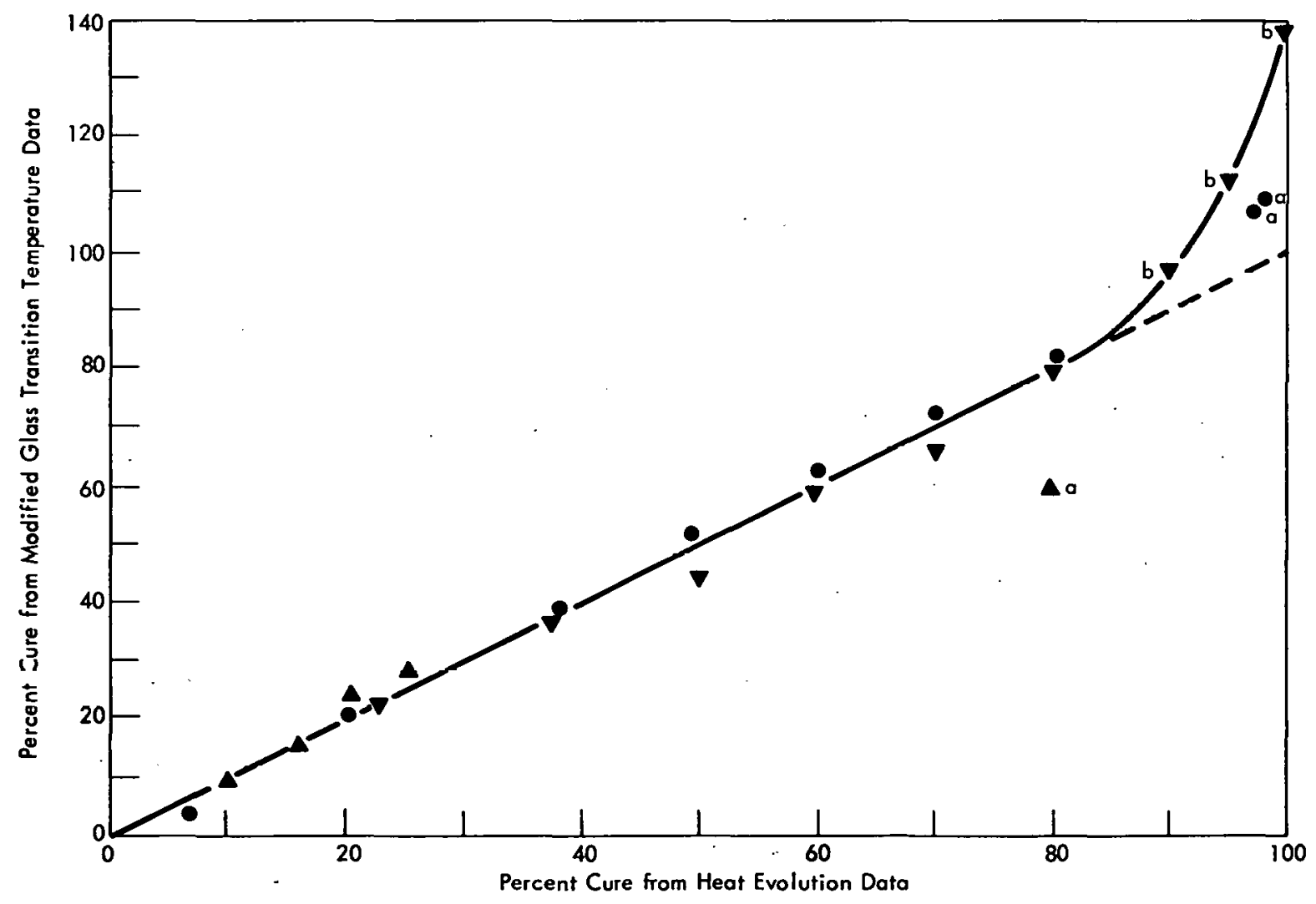

Figure 10. COMPARISON OF HEAT EVOLUTION AND MODIFIED GLASS-TRANSITION-TEMPERATURE KINETIC DATA. (The Data of Figure 9 were Replotted Using Calculated Values of $T_{g_{0}^{\prime}}=333.1 \mathrm{~K}$ and $T_{9_{\infty}^{\circ}}=434.4 \mathrm{~K}$; Points Marked " $a$ " and " $b$ " were not Used in Computing the Least-Squares Line) 




Figure 11. SECOND-ORDER KINETIC PLOT OF REVISED GLASS-TRANSITIONTEMPERATURE DATA. (The Data of Figure 6 were Replotted with $T_{g_{0}}=333.1 \mathrm{~K}$ and $T_{g}=434.1 \mathrm{~K}$; the Slopes are $\mathrm{k} 2 \mathrm{~d} / \mathrm{m}$, the Curvatures of the Data Points of .Figure 6 are not Present Here)

\section{Effects of Changes of Stoichiometry and Inert Diluents}

During the preceding discussion it was assumed that the B-staged epoxy resin consisted only of an epoxide, $E$, a stoichiometric amount of an active hydrogen compound, $H$, and some condensed polymer product, $P$. Because the results were obtained on a per-gram basis, the effect of the presence of $P$, or any other inert additive for that matter, would be that of a diluent (ie, to decrease $\Delta H$ by a factor of $1 /(1+F$ ), where $F$ is the weight fraction of additive, and to decrease reaction rates by a factor of $1 /(1+F) n$, where $n$ is the order of the reaction). Neither the determination of the order of the reaction nor of the activation energy would be affected. 
The rate of polymer formation for the second-order kinetic results obtained here is $d[P] / d t$ and is given either by:

$$
\begin{aligned}
& \frac{d[P]}{d t}=k_{2}[E][H], \\
& \frac{d[P]}{d t}=k_{2}[E]^{2}, \text { or } \\
& \frac{d[P]}{d t}=k_{2}[H]^{2},
\end{aligned}
$$

where the brackets designate the concentrations of the species. The rate is measured: directly by the DSC, but it is impossible to distinguish between Equations 4, 5, and 6 on the basis of one formulation alone. If a weight, $\Delta W_{E}$. of $E$ were added in excess of stoichiometric requirements, the concentration of $E$ would then be:

$$
[E]=\frac{1+\frac{\Delta W_{E}}{M_{E}}}{\frac{M_{E}+\Delta W_{E}}{d_{E}}+\frac{M_{H}}{d_{H}}},
$$



Figure 12. DETERMINATION OF THE ACTIVATION ENERGY FROM REVISED. GLASS-TRANSITIONTEMPERATURE DATA. (The Activation Energy is the Negative of the Slope Divided by the Gas Constant, R, and is $14.4 \mathrm{kcal} \mathrm{mol}^{-1}$, in Good Agreement with Computations Obtained from Heat-Evolution Datal

and the concentration of $\mathrm{H}$ would then be:

$$
[H]=\frac{1}{\frac{M_{E}+\Delta W_{E}}{d_{E}}+\frac{M_{H}}{d_{H}}} .
$$

where $M_{E}$ and $M_{H}$ are the molecular weights and $d E$ and $d H$ are the densities of $E$ and $H$, respectively.

Rate Expressions 4, 5, and 6 then become:

$$
\frac{d[P]}{d t}=k_{2} \frac{1+\frac{\Delta W_{E}}{M_{E}}}{\left(\frac{M_{E}+\Delta W_{E}}{d_{E}}+\frac{M_{H}}{d_{H}}\right)^{2}} .
$$




$$
\begin{aligned}
& \frac{d[P]}{d t}=k_{2} \frac{\left(1+\frac{\Delta W_{E}}{M_{E}}\right)^{2}}{\left(\frac{M_{E}+\Delta W_{E}}{d_{E}}+\frac{M_{H}}{d_{H}}\right)^{2}} \text {, and } \\
& \frac{d[P]}{d t}=k_{2} \frac{1}{\left(\frac{M_{E}+\Delta W_{E}}{d_{E}}+\frac{M_{H}}{d_{H}}\right)^{2}} \text {, }
\end{aligned}
$$

respectively, and determination of the rates of reaction of two different formulation ratios of $E$ and $H$ would demonstrate which rate law was followed. The heat of reaction per gram, $\Delta H$, is decreased by a factor expressed as:

$$
\frac{1}{\frac{M_{E}+\Delta W_{E}}{d_{E}}+\frac{M_{H}}{d_{H}}} \text {. }
$$

The effects of inert diluents on the $\mathrm{Tg}$ of polymers cover a wide range from no effect to large changes, which generally decrease the value of $\mathrm{Tg}$. Changing the ratio of $[E]$ to $[H]$ from the stoichiometric ratio would decrease the difference between $\mathrm{T}_{\mathrm{g}_{0}}$ and $\mathrm{T}_{\mathrm{g}_{\infty}}$. 


\section{REFERENCES}

(1) Horie, K., Mita, I., and Kambe, H.; J Polymer Sci, Part A-1, 6, (9), pp 2263-2276 (1968).

A. A. Duswalt in Analytical Calorimetry, R. S. Porter and J. F. Johnson, Editors; Plenum Press, New York; pp 313-317 (1968).

M. J. Uricheck, Instrument News, 17, (2); Perkin Elmer Corp, Norwalk, Connecticut (1966).

(2) Prime, R. B.; Polym Eng Sci, 13, (5), pp 365-371 (1973).

(3) Rogers, R. N.; Anal Chem, 44, (7), pp 1336-1337 (1972).

(4) Gray, A. P.; Thermal Analysis Application, Study 2; Perkin-Elmer Corporation, Norwalk, Connecticut (1972).

(5) Brennan. W. P.: Thermal Analysis Application, Study 8; Perkin-Elmer Corporation, Norwalk, Connecticut (1973).

(6) Kelley, K. K.; Contributions to the Data on Theoretical Metallurgy, XIII. High Temperature Heat Content, Heat Capacity, and Entropy Data for the Elements and Inorganic Compounds, Bulletin 584, p 90; US Bureau of Mines (1960).

(7) Ibid; $\mathrm{p} 10$.

(8) Brennan, W. P.; Thermal Analysis Application, Study 7; Perkin-Elmer Corporation, Norwalk, Connecticut (1973). 


\section{APPENDIX A}

\section{DERIVATION OF EQUATIONS FOR DETERMINING KINETIC PARAMETERS FROM ISOTHERMAL DIFFERENTIAL SCANNING CALORIMETRY DATA}

Figure 1 shows examples of DSC thermograms for exothermic reactions; here, the curing of a B-staged epoxy resin. If each molecule reacting emits or absorbs the same quantity of energy, then the area under the curve up to time $t$ is the amount of reaction which has occurred and is given by:

$$
x=\int_{0}^{t} f(h) d t
$$

where $h$ is the instantaneous heat flow rate. The total area under the curve is the heat of reaction, $\Delta \mathrm{H}$ :

$$
\Delta H=\int_{0}^{\infty} f(h) d t .
$$

\section{First-Order Reactions}

For first-order reactions:

$$
k_{1} t=\ln \left[\frac{\Delta H}{\Delta H-X}\right]
$$

where $k_{1}$ is the first-order rate constant. If it is assumed that $f(h)$ is of the form:

$$
\begin{gathered}
h=h_{0} e^{-k_{1} t} \text {, then } \\
X=\int_{0}^{t} h_{0} e^{-k_{1} t} d t=\frac{h_{0}}{k_{1}}\left(1-e^{-k_{1} t}\right) \text {, and } \\
\Delta H=\int_{0}^{\infty} h_{0} e^{-k_{1} t} d t=\frac{h_{0}}{k_{1}} .
\end{gathered}
$$

Thus:

$$
k_{1} t=\ln \left[\frac{\frac{h_{0}}{k_{1}}}{\frac{h_{0}}{k_{1}}-\frac{h_{0}}{k_{1}}\left(1-e^{-k_{1} t}\right)}\right]=\ln \frac{1}{e^{-k_{1} t}}=k_{1} t
$$


Therefore, Equation $A-1$ is the proper form for first-order reactions. Plots of In h vs $t$ give straight lines of slope $-k_{1}$ and intercept $\ln h_{0}=\ln \left(\Delta H k_{l}\right)$. Rogers $(3)$ determined $k_{1}$ from in $\mathrm{h}$ vs $\mathrm{t}$ plots, but missed the opportunity to calculate $\Delta \mathrm{H}$.

\section{Second-Order Reactions}

For second order reactions, with either initial concentrations of the two reacting species equal or with second-order dependence on one specie:

$$
k_{2} t=\frac{X}{\Delta H(\Delta H-X)}
$$

where $k_{\gamma}$ is the second-order constant. If $f(h)$ is of the form:

$$
h=h_{0}(1+g !)^{-2}
$$

where $g$ is a parameter to be determined, then:

$$
\begin{gathered}
x=\int_{0}^{t} h_{0}(1+g t)^{-2} d t=\frac{h_{0} t}{1+g t} \text {, and } \\
\Delta H=\int_{-0}^{\infty} h_{0}(1+g t)^{-2} d t=\frac{h_{0}}{g} .
\end{gathered}
$$

Substituting Equations $A-3$ and $A-4$ into Equation A-2 gives:

$$
k_{2} t=\frac{g t}{1+g t} \frac{g(1+g t)}{h_{o}}=\frac{g^{2} t}{h_{0}}
$$

Thus:

$$
\begin{aligned}
& k_{2}=\frac{g^{2}}{h_{0}} \text {, and } \\
& k_{2} \frac{1}{(1+g t)^{2}}=\frac{1}{k_{2}}\left[\frac{1}{\frac{1}{g}+t}\right]^{2} \text {, and } \\
& \Delta H=\frac{g}{k_{2}} .
\end{aligned}
$$


Equation A-5 can be rewritten:

$$
\frac{1}{h^{1 / 2}}=k_{2}^{1 / 2} t+\frac{k_{2}^{1 / 2}}{g} \text {. }
$$

and a plot of $h^{-1 / 2}$ vs $t$ will give a straight line of slope $k_{2}{ }^{1 / 2}$ and intercept $k_{2}^{1 / 2} / g$.

The fraction reacted after time $t$ is:

$$
\frac{X}{\Delta H}=\frac{g t}{1+g t}=\frac{\Delta H_{2} t}{1+\Delta H_{2} t} .
$$

from which it is easily seen that $g$ is the reciprocal of the half time.

From the Arrhenius equation:

$$
k_{n}(T)=k_{n}^{\circ} e^{-E^{\ddagger} / R T}
$$

where $E^{\ddagger}$ is the activation energy and $R$ is the gas constant, the temperature dependence of the $\mathrm{g}$ parameter is easily shown to be:

$$
g(T)=g_{O} e^{-E^{\ddagger} / R T}
$$

The activation energy is normally found from the slope of a plot of $\ln k_{n}$ vs $T^{-1}$.

\section{Third-Order Reactions}

Assume a solution of the form:

$$
h=h_{u}(1+\mid t)^{-3 / 2} \text {, }
$$

where I is a parameter to be determined.

Thus:

$$
\begin{gathered}
x=\int_{0}^{t} h_{0}\left(1+(t)^{-3 / 2} d t=\frac{2 h_{0}}{c}\left[1-(1+t \mid t)^{-1 / 2}\right],\right. \text { and } \\
\Delta H=\int_{0}^{\infty} h_{0}(1+t t)^{-3 / 2} d t=\frac{2 h_{0}}{1} .
\end{gathered}
$$


For third-order reactions:

$$
k_{3} t=1 / 2\left[\frac{1}{(\Delta H-X)^{2}}-\frac{1}{\Delta H^{2}}\right]=\frac{\beta_{t}}{8 h_{0}{ }^{2}} .
$$

Then:

$$
\begin{aligned}
& k_{3}=\frac{1^{3}}{8 h_{0}^{2}}, \text { or } \\
& h_{0}=\left(\frac{1^{3}}{8 k_{3}}\right)^{1 / 2} .
\end{aligned}
$$

Thus:

$$
h=\left[\frac{1^{3}}{8 k_{3}}\right]^{1 / 2}(1+\mid t)^{3 / 2}
$$

Upon raising this expression to the $-2 / 3$ power:

$$
h^{-2 / 3}-\frac{2 k 3^{1 / 3}}{1}(1 \quad l \mid t)=2 k \cdot 3^{1 / 3} t+\left.2 k_{3}{ }^{1 / 3}\right|^{-1}
$$

Plots of $\mathrm{h}^{-2 / 3}$ vs $t$ give straight lines of slope $2 k_{3} 3^{1 / 3}$ and intercept $\left.2 k_{3} 3^{1 / 3}\right|^{-1}$. The slope-intercept ratio is $\mathrm{I}$. The fraction reacted at time $\mathrm{t}$ is:

$$
\frac{x}{\Delta H}=1-(1+\mid t)^{-1 / 2}
$$

from whlch it caan be shown that the concentration of the reacting species, $c$, is:

$$
c=\frac{3}{t_{1 / 2}} \text {. }
$$

where $t_{1 / 2}$ is the half time of the reaction.

Similar methods can be used to derive equations for other reaction orders. It should be noted that uncertainties in the time of initiation will not affect the determination of the rate and activation energy. Corrections of the other parameters can be made easily by computing intercepts from values of $\Delta \mathrm{H}$ determined by standard techniques. 


\section{APPENDIX B}

\section{DERIVATION OF EQUATIONS FOR DETERMINING KINETIC PARAMETERS FROM GLASS-TRANSITION-TEMPERATURE DATA}

The glass transition temperature, $\mathrm{T}_{\mathrm{g}}$, is that temperature (or, more correctly, temperature range) at which, upon heating, an amorphous material changes from a glassy to a liquid state. It can be determined from heat-capacity or thermal-expansion curves.

For many polymers, the empirical formula:

$$
T_{g}=m M^{-1}+b
$$

has been found, (3) where $M$ is the molecular weight, $m$ the slope, and $b$ the intercept. Thus, as $M \rightarrow \infty$ and $T_{g} \rightarrow T_{g_{\infty}}$, the $T_{g}$ at infinite molecular weight, or complete cure, $T_{g_{\infty}}$ must be b. Because:

$$
M=\frac{d}{c} \text {. }
$$

where $d$ is the density and $c$ the concentration,

$$
\begin{aligned}
& \frac{d}{c}=\frac{m}{T_{g}-T_{g_{\infty}}}, \text { or } \\
& c=\frac{d}{m}\left(T_{g}-T_{g_{\infty}}\right) .
\end{aligned}
$$

Initially:

$$
\begin{aligned}
& \frac{d}{c_{O}}=\frac{m}{T_{g_{u}}-T_{g_{w}}}, \text { or } \\
& c_{O}=\frac{d}{m}\left(T_{g_{O}}-T_{g_{\infty}}\right) .
\end{aligned}
$$

The fraction reacted is thus given by:

$$
\frac{\left(c_{0}-c\right)}{c_{0}}=\frac{T_{g_{0}}-T_{g}}{T_{g_{0}}-T_{g_{\infty}}} \text {. }
$$

regardless of the kinetic order of the reaction. 
For first-order reactions:

$$
\frac{c}{c_{0}}=e^{-k_{1} t}
$$

where $k_{1}$ is the first-order rate constant, and $t$ is the time passed since the initiation of the reaction. Substituting Equations B-1 and B-2 (or B-3) into Equation B-4:

$$
\frac{T_{g}-T_{g_{\infty}}}{T_{g_{0}}-T_{g_{\infty}}}=e^{-k_{1} t}
$$

Plots of $\ln \left[\frac{T_{g_{0}}-T_{g_{\infty}}}{T_{g}-T_{g_{\infty}}}\right] v s$ t give straight lines passing through the origin with $k_{1}$ as the slope.

For all other reaction orders:

$$
\frac{1}{n-1}\left[\frac{1}{c^{n-1}} \cdot \frac{1}{c_{0}^{n-1}}\right]-k_{n} t
$$

where $k_{n}$ is the $n^{\text {th }}$ order rate constant. Substituting Equations B-1 and B-2 into Equation B-5 gives:

$$
k_{n} t=\frac{m^{\prime 1-1}}{d^{n-1}(n-1)}\left[\frac{1}{\left(T_{g_{\infty}}-T_{g}\right)^{n-1}}-\frac{1}{\left(T_{g_{\infty}}-T_{g_{0}}\right)^{n-1}}\right]
$$

Plots of $\left(T_{g_{\infty}}-T_{g}\right)^{1-n}$ vs $t$ give straight lincs passing through the origin with slopes of $\frac{k_{n} d^{n-1}(n-1)}{m^{n-1}}$ and intercepts of $\left(T_{g_{\infty}}-T_{g_{0}}\right)^{1-n}$.

The rate constants, $k_{n}$, are the same as those in Appendix $A$. Thus, by determining the density, $m$ can be determined trom a combination of a rate constant obtained from heat evolution data and the term $k_{n} d^{n-1}(n-1) / m^{n-1}$ obtained from $T_{q}$ data for the same heat-treatment temperature. Thereafter, the molecular weight of a sample can be found from a $\mathrm{T}_{\mathrm{g}}$ measurement. 


\section{APPENDIX C}

\section{USE OF KINETIC PARAMETERS IN DETERMINING EXTENT OF CURE}

Disappearance of a reactant at concentration $\mathrm{c}$ is given by:

$$
\frac{-d c}{d t}=c^{n_{k_{n}}} o^{-\frac{E^{\ddagger}}{R(T+p t)}}
$$

where $t$ is the time, $n$ the order of reaction, $k_{n}{ }^{0}$ the Arrhenius or frequency factor, $(c) E^{\ddagger}$ the activation energy, $R$ the gas constant, $T$ the initial temperature, and $p$ the rate of temperature change. For isothermal, second order reactions, Equation $\mathrm{C}-1$ may be rearranged and integrated to give:

$$
\begin{aligned}
& \left.\left.\frac{1}{c}\right]_{C_{O}}^{c}=k_{2}{ }^{o} t e^{-E^{\ddagger} / R T}\right]_{0}^{t} \text {, or } \\
& \frac{1}{c}-\frac{1}{c_{o}}=k_{2} o_{t e}-E^{\ddagger} / R T .
\end{aligned}
$$

For second-order, nonisothermal reactions with $p$ constant, but not zero:

$$
\frac{1}{c}-\frac{1}{c_{0}}=\int_{0}^{t} k_{2} e^{o-E^{\ddagger} / R(T+p t)} d t .
$$

Using the series expansion:

$$
e^{x}=\sum_{n=0}^{\infty} \frac{x^{n}}{n !}
$$

Equation C-2 may be integrated stepwise to give:

$$
\begin{gathered}
\frac{1}{c}-\frac{1}{c_{0}}=k_{2} 0\left\{t-\frac{E^{\ddagger}}{R p} \ln \left(\frac{T+p t}{T}\right)-\frac{1}{p} \sum_{n=2}^{\infty}\left[( \frac { C ^ { \ddagger } } { R } ) ^ { n } \cdot \frac { 1 } { ( n - 1 ) n ! } \left((T+p t)^{1-n}-\right.\right.\right. \\
\left.T^{1-n)}\right)
\end{gathered}
$$

(c) It was assumed for ease of computation that $k_{n}{ }^{0}$ was independent of temperature.

(d) The series in the third term converges slowly and requires carrying a large number of significant digits. 
As an example, samples of as-received, B-staged resin were heat treated in the following manner: Heated from 323 to $423 \mathrm{~K}$ at $p=1.25 \mathrm{deg} \mathrm{min}^{-1}$, held at $423 \mathrm{~K}$ for 30 minutes, and cooled from 423 to $323 \mathrm{~K}$ at $p=-1.25 \mathrm{deg} \mathrm{min}^{-1}$. It was assumed that the reaction started when the temperature reached $\mathrm{T}_{\mathrm{g}}^{\prime}(433 \mathrm{~K})$.

A Simpson's-rule integration of Equation $\mathrm{C}-2$, with $\Delta t=240$ seconds for the heating and holding parts of the cycle, gives:

$$
\begin{aligned}
& \frac{1}{c}-\frac{1}{c_{0}}=\frac{1}{3} \times 240\left[K_{333}+K_{423}+4\left(K_{338}+K_{348}+\ldots\right)+\right. \\
& \left.2\left(K_{343}+K_{353}+\ldots\right)\right]+k_{2}{ }^{0} \times 1800 e^{-14,800 / 1.987 \times 423},
\end{aligned}
$$

where the $K_{T} s$ are the values of $k_{2}{ }^{\circ} e^{-E \neq / \bar{R} \bar{T}}$ at $T$.

Equation A-8 can be rewritten as:

$$
\frac{X}{\Delta H}=\frac{\Delta H\left(\frac{1}{c}-\frac{1}{c_{O}}\right)}{1+\Delta H\left(\frac{1}{c}-\frac{1}{c_{O}}\right)}
$$

The extent of reaction after the $1.25 \mathrm{deg} \mathrm{min}^{-1}$ heat and $423 \mathrm{~K}$ hold was computed from Equations $\mathrm{C}-4$ and $\mathrm{C}-5$ to be $64.0 \%$. From Figure 8 , the $\mathrm{T}_{\mathrm{g}}$ at that point was $399 \mathrm{~K}$. It was therefore decided that the reaction would probably cease when $403 \mathrm{~K}$ was reached on the cooling portion of the heat-treatment cycle. A third term was added to Equation C-4 to account for the reaction occurring upon cooling to $403 \mathrm{~K}$ giving:

$$
\begin{gathered}
\frac{1}{c}-\frac{1}{c_{o}}=\frac{240}{3}\left[k_{333}+k_{423}+4\left(K_{338}+k_{348}+\ldots\right)+2 .\left(K_{343}+K_{353}+\ldots\right)\right] \\
+1800 k_{2} e^{-14,800 / 1.987 \times 423} \\
+\frac{240}{3}\left[K_{423}+K_{403}+4\left(K_{418}+K_{408}\right)+2 K_{113}\right]
\end{gathered}
$$

The percent of reaction, calculated by substituting the result of Equation C- 6 into Equation $\mathrm{C}-5$, was $68.6 \%$. A two-minute anneal at $423 \mathrm{~K}$ was needed to eliminate the very sharp endothermic spike found after the heat-treatment cycle, and a $\mathrm{Tg}_{\mathrm{g}}$ of $407.0 \mathrm{~K}$ was then obtained in the usual manner. The degree of cure can be determined from $T_{g}$ in two ways: (1) from Equation B-3, using $\mathrm{T}_{g_{0}}=333.1 \mathrm{~K}$ and $\mathrm{T}_{g_{\infty}}=434.4 \mathrm{~K}$, a $\mathrm{Tg}_{\mathrm{g}}$ of $407.0 \mathrm{~K}$ corresponds to a $73.0 \%$ cure; (2) from Figure 8, a $\mathrm{Tg}$ of $407.0 \mathrm{~K}$ corresponds to a $73.6 \%$ cure. Both of these ways compare very well with the $68.6 \%$ computed from rate-of-heat-evolution data. 


\section{Distribution}

Energy Research and Development

Administration - Oak Ridge

Hickman, H. D.

Leed, R. E.

Zachry, D. S., Jr

Lawrence Livermore Laboratory

Nelson, W. E.

Los Alamos Scientific Laboratory

Hoyt, H. C.

Oak Ridge Gaseous Diffusion Plant

Stief, S. S.

Wilcox, W. J., Jr

Oak Ridge National Laboratory

Weir, J. R., Jr

Oak Ridge Y-12 Plant

Armstrong, R. C.

Basford, J. A. (25)

Bernander, N. K.

Briscoe, O.W.

Burditt, R. B.

Burkhart, L. E./Mason, D. L.

Dorsey, G. F.

Duggan, H. G.

Ebert, T. H.

Fraser, R. J.

Jones, F. W.

Kahl, K. G.

Keith, A.

Kite, H. T.

Marrow, G. B.

McLendon, J. D.

Mills, J. M., Jr

Phillips, L. R.

Rowan, J. H.

Rutenberg, A. C.
Schreyer, J. M.

Smith, H. F., Jr

Smith, R. D.

Smith, W. E.

Tewes, W. E.

Thompson, C. H.

Weathersby, W. E.

Whitehead, H. D.

Yaggi, W. J./Googin, J. M.

$Y-12$ Central Files (master copy)

Y-12 Central Files (route copy)

$Y-12$ Central Files ( $Y-12 R C$ )

$Y-12$ Central Files (5)

Zava, A. K.

Zerby, C. D.

Sandia - Albuquerque

Hillman, J. T.

Paducah Gaseous Diffusion Plant Levin, R. W.

\section{Union Carbide Corporation -} New York

Winters, Charles

Union Carbide Corporation Parma Research Center

Chambers, W. E.

University of Tennessee -

College of Engineering

Stansberry, E. E.

In addition, this report is distributed in accordance with the categories UC-25 and UC-37. Materials and Instruments, as given in the USERDA Standard Distribution Lists for Unclassified Scientific and Technical Reports, TID-4500. 